\title{
Coronavirus shows how UK must act quickly before being shut out of Europe's health protection systems
}

The threat posed by 2019-nCoV and the fragmentation of existing health protection systems caused by Brexit call for urgent assessment of cross Europe cooperation, say Mark Flear, Anniek de Ruijter, and Martin McKee

\section{Mark Flear reader in law ${ }^{1}$, Anniek de Ruijter associate professor ${ }^{2}$, Martin McKee professor of European public health ${ }^{3}$}

${ }^{1}$ Queen's University Belfast, Belfast, UK; ${ }^{2}$ Amsterdam Law School, Amsterdam, Netherlands; ${ }^{3}$ London School of Hygiene and Tropical Medicine, London, UK

\begin{abstract}
Health authorities worldwide are racing to contain the spread of the coronavirus 2019-nCoV, identified as the cause of the outbreak that began in Wuhan, China, at the end of last year. By 31 January more than 9600 people were reported to have been infected in China, with around 200 deaths, and cases have also been reported elsewhere in Asia and in North America, Australia, and Europe, including France, Finland, Germany, and now the UK. ${ }^{1}$ The case in Germany is especially worrying as it was in someone who had not travelled to China but who had been in contact with someone who had. Unprecedented measures, including lockdowns of large cities in China and widespread flight cancellations, are being adopted.
\end{abstract}

The international response to major outbreaks of infectious disease is coordinated by the World Health Organization and is based on its International Health Regulations. ${ }^{2}$ Europe also has a regime for communicable disease control, ${ }^{3}$ centred on the Stockholm based European Centre for Disease Prevention and Control (ECDC), which has a crucial role in responding to threats to health in the continent.

Given the UK's departure from the European Union, we argue that the coronavirus outbreak is an urgent warning highlighting the need to reflect on what Brexit might mean for the country's health security. We review how that system operates and what the implications might be for the UK. In doing so we draw on the experience of Switzerland. Like a post-Brexit UK, Switzerland is outside the EU and, specifically, the single market. As a consequence it is excluded from many elements of the EU's disease control structures. ${ }^{4}$

\section{European cooperation}

The WHO and EU processes, including their alert levels, are closely aligned, ${ }^{56}$ and the International Health Regulations specify that they and the EU treaties "should be interpreted so as to be compatible." Even after Brexit the UK will continue to participate in WHO's system, but its relationship with the EU system is far less clear.

This is important, because the EU regime involves a much deeper level of cooperation than WHO's. This reflects the close relationships that exist within the EU, including freedom of movement for goods and persons. Besides the European Centre for Disease Prevention and Control, the EU regime includes an emergency mechanism for the approval of pandemic medicines, joint public procurement, and the Early Warning and Response System, ${ }^{7}$ which encompasses other cross border threats to health. ${ }^{8}$ The EWRS and wider health security mechanisms provide the basis for a coordinated EU-wide response.

Any infection such as the new coronavirus that poses a serious hazard to health and that has spread across national borders of EU member states must be notified via the EWRS, and the data are collated into regular reports by the ECDC. ${ }^{9}$ These data then inform decisions by the EU Health Security Committee, where all member states and the European Commission decide how to respond consistently. This could include invoking an urgency procedure for a central marketing authorisation of pandemic vaccines and joint procurement. ${ }^{810}$

An obvious weakness of the EU regime is that it does not extend beyond the borders of the European Economic Area, which includes EU countries and also Iceland, Liechtenstein, and Norway. These three countries also participate in the EU's regime, as they are members of the single market, and work closely with the ECDC. Other countries also participate in some of the activities of the EWRS, including EU candidate countries, Switzerland, and the European microstates such as Monaco and San Marino. But their participation is under the framework of 
the International Health Regulations, which govern their level of engagement. Crucially, as they lie outside the EU's legal system, including oversight by the EU's Court of Justice (or equivalent arrangements for the EEA), they are unable to participate in the exchange of much of the data required for effective surveillance or in certain mechanisms to coordinate responses.

\section{What does this mean for a post-Brexit UK?}

At first, little will change for the UK after Brexit because, although it will no longer have any say in the EU's decision making processes, under the withdrawal agreement it will continue to participate in EU arrangements until the end of the transition period on 31 December 2020. ${ }^{11}$ Thus the UK will retain access to the EWRS under these arrangements until then. After that, the situation is much less certain, not least because the UK government seems unsure about the nature of its future relationship with the EU. Now that the UK has withdrawn from the Joint Procurement Agreement and the European Medicines Agency, it will no longer have the same level of access to medical countermeasures, including those developed through the urgent market authorisation procedure. Manufacturers of these countermeasures are likely to prioritise market authorisation in the EU over the UK's far smaller market. ${ }^{12} 13$

Obviously, as infections can travel in any direction, the EU and (in the future) the UK have a common interest in the closest possible cooperation. British politicians often use this argument, saying that little will actually change with Brexit. However, just because something may be desirable doesn't mean it's possible. Switzerland offers an example of the challenges involved, although its experience should be interpreted in the light of its much closer relationship with the EU, including free movement of people, than what is proposed by the UK government.

As we noted above, Switzerland and a post-Brexit UK will participate in WHO's regime. However, despite the commitment to close alignment of the EU and WHO regimes, in practice there can be problems when coordination is not properly regulated in advance of a crisis. Interviews with people involved with the swine flu outbreak in 2009 described "panic" arising from confusion over the roles of $\mathrm{WHO}$, the EU, and its member states, ${ }^{5}$ though cooperation between ECDC and WHO has improved over the past decade.

ECDC does cooperate with other countries, such as the US, China, and Israel, ${ }^{14}$ but these arrangements fall far short of what until now has been possible for the UK as a member of the EU, especially in areas such as data exchange, drug authorisations, and vaccine procurement.

Switzerland's experience is salutary. ${ }^{4}$ When $2019-n C o V$ emerged, the Swiss government asked the EU to give it temporary access to the EWRS. From a public health perspective the case for doing so is obvious. Yet Switzerland is unlikely to obtain permanent access because of ongoing disputes over its refusal to automatically adopt single market rules, a problem with clear relevance to a post-Brexit UK. As the head of the communicable diseases unit at the Swiss Federal Department of Health, said, "What it shows now is that when a crisis starts, it's a little bit late to put us in, it takes too much time."4

\section{European vulnerability demands European solutions}

By removing an important communication channel between the UK and EU, Brexit poses a threat to infectious disease control and-given the wide remit of the EU regime-wider risks to health in both jurisdictions. As the Swiss experience shows, the argument that things will work out because it is in the interest of both sides that they do is misconceived and dangerously complacent.

There are ways for countries outside the EU to engage with its structures and processes, as is the case with Norway, Iceland, and Liechtenstein. But this engagement requires that the country in question agrees to participate in the single market or at least commits to close alignment with it. This would require that it adopts legislation of "equivalent effect" to that in the EU, which would again include rules on data protection. ${ }^{2}$ The UK has made it clear that it will not be a "rule taker," a position that would seem to close off these opportunities, even though doing so poses a threat to itself and to other countries. ${ }^{15}$

Cooperation across Europe is vital if individual countries and the continent as a whole are to be protected from threats to life and health posed by emerging and re-emerging infections and other public health risks. The UK government is entitled to choose how closely it aligns with the EU. But in doing so it must recognise that its decision has consequences for the health of its citizens and those of its European neighbours. ${ }^{16}$

1 Mahase E. China coronavirus: WHO declares international emergency as death toll exceeds 200. BMJ 2020;368:m408.

2 World Health Organization. Strengthening health security by implementing the International Health Regulations (2005). https://www.who.int/ihr/en.

3 European Union. Regulation (EC) 851/2004 of the European Parliament and of the Council of 21 April 2004 establishing a European Centre for Disease Prevention and Control. Official Journal of the European Union 2004;47:L142.

4 Miller J. Swiss seek access to EU early-warning system as coronavirus spreads. Swissinfo Jan 2020. https://www.swissinfo.ch/eng/reuters/swiss-seek-access-to-eu-early-warningsystem-as-coronavirus-spreads/45523616.

5 de Ruijter A. EU health law \& policy: the expansion of EU power in public health and health care. Oxford University Press, 201910.1093/oso/9780198788096.001.0001.

6 Flear M. Governing public health: EU law, regulation and biopolitics. Bloomsbury Publishing, 2015

7 European Centre for Disease Prevention and Control. Early Warning and Response System of the European Union (EWRS) 2020. https://www.ecdc.europa.eu/en/publicationsdata/early-warning-and-response-system-european-union-ewrs.

8 European Union. Decision 1082/2013/EU on serious cross-border threats to health and repealing Decision 2119/98/EC. Official Journal of the European Union 2013;L293/1.

9 European Centre for Disease Prevention and Control. Novel coronavirus in China 2020. https://www.ecdc.europa.eu/en/novel-coronavirus-china accessed 29th January 2020.

10 de Ruijter A. Mixing EU security and public health expertise in the health threats decision. In: de Ruijter A, Weimer M, eds. Regulating risks in the European Union. Hart Publishing, 201710.2139/ssrn.3104489.

11 European Union. Agreement on the withdrawal of the United Kingdom of Great Britain and Northern Ireland from the European Union and the European Atomic Energy Community [2019] (Withdrawal Agreement). Official Journal of the European Union 2019;C384 I/1.

12 Elborn S, Flear M, Downey D. Implications of "no deal" Brexit for orphan and paediatric medicines. BMJ Opinion 2019. https://blogs.bmj.com/bmj/2019/07/19/implications-of-nodeal-brexit-for-orphan-and-paediatric-medicines.

13 Bastos FB, de Ruijter A. Break or bend in case of emergency? Rule of law and state of emergency in European public health administration. Nov 2019. Amsterdam Law School research paper 2019-38.

14 European Centre for Disease Prevention and Control. ECDC partnerships 2020. https:// www.ecdc.europa.eu/en/about-us/who-we-work/ecdc-partnerships.

15 Armstrong K. "Brexternalities," Article 50 and the UK's grossly irresponsible attempt to export its own problems. Prospect. Jan 2020 https://www.prospectmagazine.co.uk/world/ brexternalities-article-50-and-the-uks-grossly-irresponsible-attempt-to-export-its-ownproblems.

16 Fahy N, Hervey T, Greer S, etal . How will Brexit affect health services in the UK? An updated evaluation. Lancet 2019;393:949-58. 10.1016/S0140-6736(19)30425-8 30819519

Published by the BMJ Publishing Group Limited. For permission to use (where not already granted under a licence) please go to http://group.bmj.com/group/rights-licensing/ permissions 